\title{
Napawanie utwardzające stali 14MoV6-3
}

\author{
The hard -surfacing steel 14MoV6-3
}

\section{Streszczenie}

W artykule zaprezentowano wyniki badań napoin wykonanych proszkiem stellitowym o różnym składzie chemicznym na stali 14MoV6-3. Wykonano badania metalograficzne i pomiary twardości napoin przed i po obróbce cieplnej.

Słowa kluczowe: napoina; struktura; twardość

\section{Abstract}

The article presents the results of welds performed stellit powder with different chemical compositions on steel 14MoV6-3. Metallographic test and weld hardness before and after heat treatment was performed.

Keywords: weld; structure; hardness

\section{Wstęp}

Olbrzymie koszty związane ze zużyciem i niszczeniem części maszyn wymuszają na konstruktorach dążenie do ich zmniejszenia poprzez projektowanie maszyn, których powierzchnie robocze są wykonane $z$ materiałów o specjalnych własnościach, z możliwością ich wielokrotnego regenerowania. Jedna z metod pozwalających na ograniczenie szybkiego zużycia jest nakładanie powłok metodami spawalniczymi.

Postęp jaki nastąpił w inżynierii materiałowej, technologiach spawalniczych, elektronice i elektrotechnice umożliwia napawanie przedmiotów wykonanych z różnych materiałów konstrukcyjnych o dowolnym kształcie i wielkości. Prace te mogą być prowadzone zarówno ręcznie, jak i półautomatycznie, automatycznie lub w sposób zrobotyzowany, w warunkach warsztatowych i polowych [1].

Do napawania utwardzającego często wykorzystuje się stellity. Są to stopy na osnowie kobaltu zawierające od $25 \%$ do $33 \%$ chromu, od $3 \%$ do $14 \%$ wolframu i od $0,7 \%$ do $3 \%$ węgla. Stellity charakteryzują się dużą odpornością na ścieranie i korozję w wysokiej temperaturze, są odporne również na utlenianie i erozję. Stellity dobrze sprawują się jako powierzchnie uszczelniające $\mathrm{w}$ armaturze przemysłowej pracującej w instalacjach o wysokich parametrach [2].

\section{Badania własne}

Badaniom poddano gniazda zaworów napawane proszkiem stellitowym o różnym składzie chemicznym (tabl.l) na stali 14MoV6-3 (tabl. II).

Materiał napawano plazmowo na automacie spawalniczym PPP 250 WP produkcji KSK Czeska Trebova. Po napawaniu elementy poddano obróbce cieplnej, zgodnie z zaleceniami

Tablica I. Skład chemiczny napoin [3]

Table I. Chemical composition of welds [3]

\begin{tabular}{|c|c|c|c|c|c|c|c|c|c|c|c|}
\hline \multirow{2}{*}{ Próbka } & \multirow{2}{*}{$\begin{array}{c}\text { Stellit } \\
\text { (producent) }\end{array}$} & \multicolumn{10}{|c|}{ Skład chemiczny [\%] } \\
\hline & & C & Si & $M n$ & $\mathrm{Cr}$ & Mo & $\mathrm{Ni}$ & Mo & W & $\mathrm{Fe}$ & Co \\
\hline 6 & $\begin{array}{c}\text { STELLORIC } \\
1372 \\
\text { (ORIC) }\end{array}$ & 1,37 & 1,60 & 0,19 & 28,6 & 0,05 & 2,12 & 0,05 & 8,87 & 1,35 & 55,8 \\
\hline M6M6 & $\begin{array}{c}\text { Most } \\
\text { EL-C0 } 6 \text { P4 } \\
\text { (Most) }\end{array}$ & 1,67 & 1,33 & 0,1 & 29,80 & 0,01 & 0,40 & 0,01 & 8,70 & 1,20 & 56,78 \\
\hline 1 & $\begin{array}{c}\text { EL-Co } 1 \mathrm{~W} \\
\text { (Most) }\end{array}$ & 2,2 & 1,2 & - & 30,6 & - & 1 & - & 12,7 & 0,2 & 52,1 \\
\hline 12 & $\begin{array}{c}\text { DEW } \\
\text { CELSIT V-P } \\
\text { (DEW) }\end{array}$ & 1,04 & 1,39 & 0,11 & 28,5 & 0,08 & 1,37 & 0,08 & 4,25 & 1,39 & 61,79 \\
\hline
\end{tabular}

Dr inż. Anna Pocica - Politechnika Opolska; inż. Adam Krzywdziński - Fabryka Armatury Przemysłowej „Wakmet” Bodzanów. Autor korespondencyjny/Corresponding author. a.pocica@po.opole.pl 
Tablica II. Skład chemiczny stali 14MoV6-3

Table II. Chemical composition of the steel 14MoV6-3

\begin{tabular}{|c|c|c|c|c|c|c|c|}
\hline \multicolumn{9}{|c|}{ Skład chemiczny [\%] } \\
\hline $\mathbf{C}$ & $\mathbf{M n}$ & $\mathbf{S i}$ & $\mathbf{P}$ & $\mathbf{S}$ & $\mathbf{C r}$ & $\mathbf{N i}$ & Mo \\
\hline 0,13 & 0,58 & 0,20 & 0,011 & 0,009 & 0,48 & 0,120 & 0,53 \\
\hline $\mathbf{C u}$ & $\mathbf{A l}$ & $\mathbf{N}$ & $\mathbf{V}$ & $\mathbf{S n}$ & $\mathbf{C o}$ & $\mathrm{As}$ & $\mathrm{Ti}$ \\
\hline 0,16 & 0,012 & 0,006 & 0,25 & 0,01 & 0,008 & 0,006 & 0,003 \\
\hline
\end{tabular}

podanymi przez Instytut Spawalnictwa w Gliwicach. Po zamontowaniu termopar próbki położono na macie grzewczej i przykryto wełną ceramiczną. Matę i termopary podłączono do urządzenia sterującego procesem obróbki firmy LMS z Chorzowa. Próbki nagrzewano z prędkością $150^{\circ} \mathrm{C} / \mathrm{h}$ do temperatury $500{ }^{\circ} \mathrm{C}$ i wytrzymano $\mathrm{w}$ tej temperaturze przez godzinę. Następnie zwiększono prędkość nagrzewania do temperatury $710{ }^{\circ} \mathrm{C}$ (rys. 1) i wytrzymano w tej temperaturze przez kolejną godzinę. Napoiny chłodzono z szybkością nie przekraczającą $150^{\circ} / \mathrm{h}$. Próbki obrobione cieplnie zostały oznaczone cyfrą "1" na końcu nazwy.

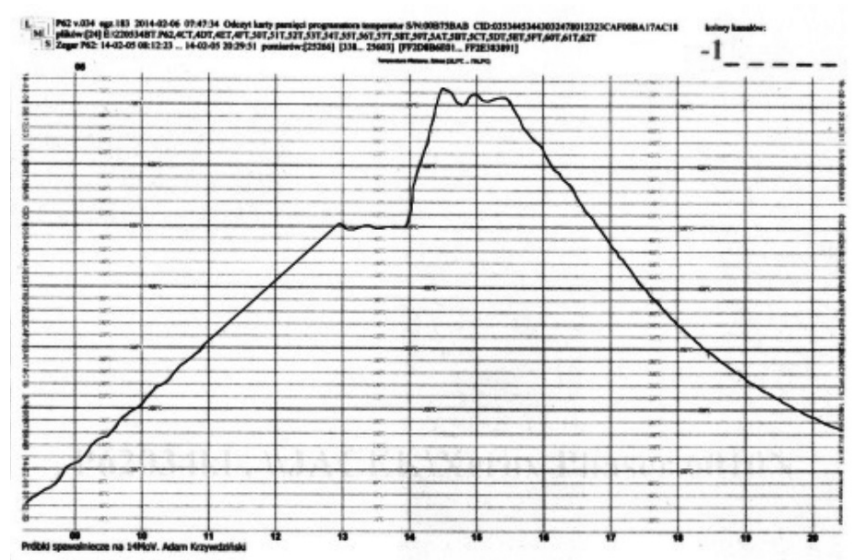

Rys. 1. Schemat obróbki cieplnej

Fig. 1. The diagramof heat treatment

Z przygotowanych napoin wycięto próbki do badań metalograficznych i pomiarów twardości. Zgłady szlifowano na papierach ściernych, następnie polerowano i trawiono Nitalem. Obserwacji dokonano na mikroskopie Neophot 2, stosując powiększenia 200x. Pole obserwacyjne obejmowało napoiny, strefę wpływu ciepła oraz materiał rodzimy. Zaobserwowane struktury przedstawiono na rysunkach $2 \div 5$.

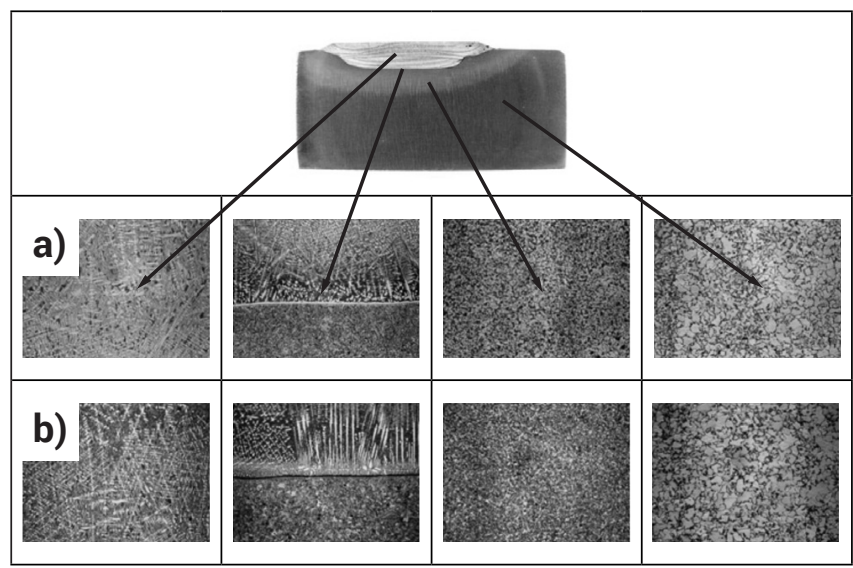

Rys. 2. Struktura napoiny ze stellitu EL-Co 1 W. Pow. 200x, przed obróbką cieplną, b) po obróbce cieplnej

Fig. 2. The structure of weld with stellite EL-Co1 W. Magnification 200x, before the heat treatment, b) after the heat treatment

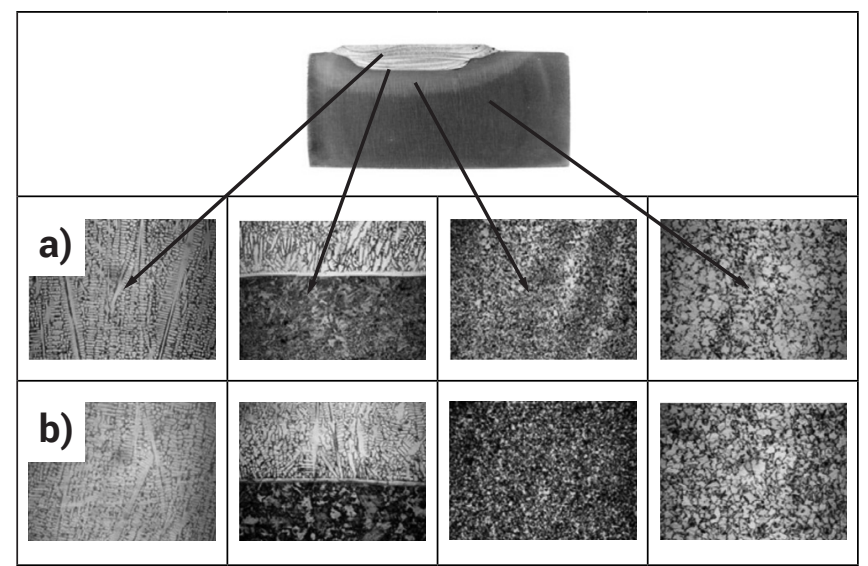

Rys. 3. Struktura napoiny ze stellitu STELLORIC 1372. Pow. 200x, a) przed obróbką cieplną, b) po obróbce cieplnej

Fig. 3. The structure of weld with stellite STELLORIC 1372. Magnification 200x, before the heat treatment, b) after the heat treatment

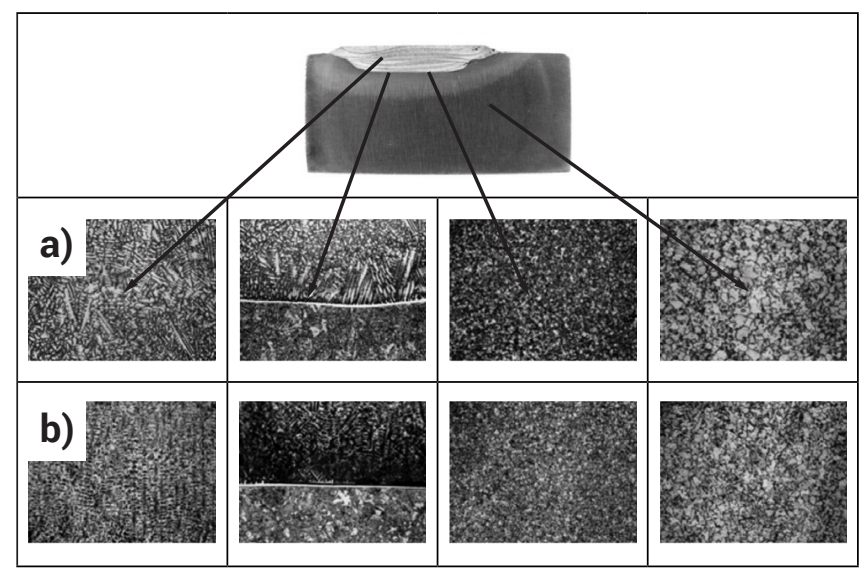

Rys. 4. Struktura napoiny ze stellitu Most EL-CO 6 P4. Pow. 200x, a) przed obróbką cieplną, b) po obróbce cieplnej

Fig. 4. The structure of weld with stellite Most EL-CO 6 P4. Magnification 200x, before the heat treatment, b) after the heat treatment

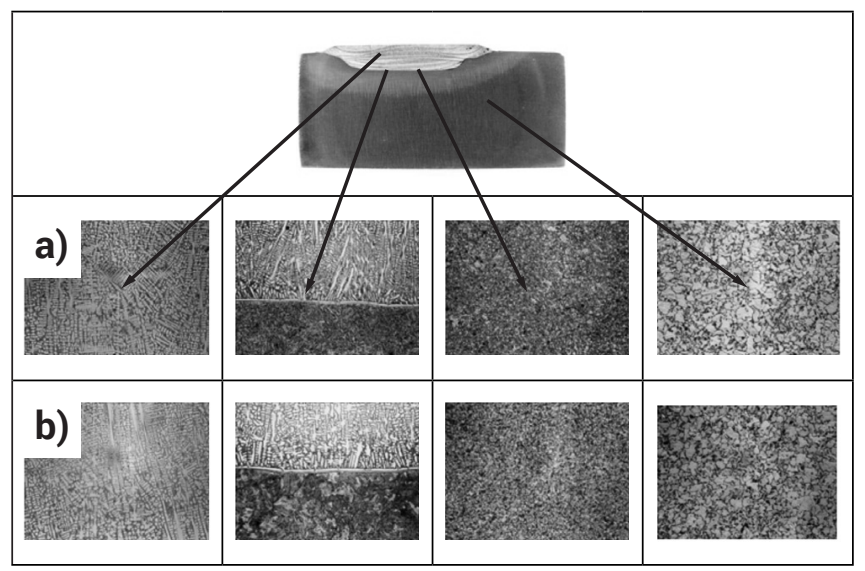

Rys. 5. Struktura napoiny ze stellitu DEW CELSIT V-P. Pow. 200x, a) przed obróbką cieplną, b) po obróbce cieplnej

Fig. 5. The structure of weld with stellite DEW CELSIT V-P. Magnification 200x, before the heat treatment, b) after the heat treatment 
2400/60/16. Badania przeprowadzono zgodnie z PN-EN IS06507-1, PN-EN IS09015-1, stosując obciążenie $98 \mathrm{~N}$. Schemat pomiaru twardości przedstawiono na rysunku 6 , a wyniki pomiarów na rysunku 7.

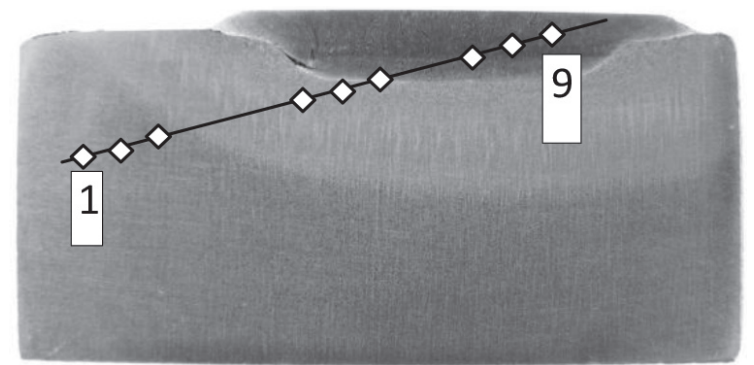

Rys. 6. Schemat pomiaru twardości napoin

Fig. 6. Hardness measurement diagram

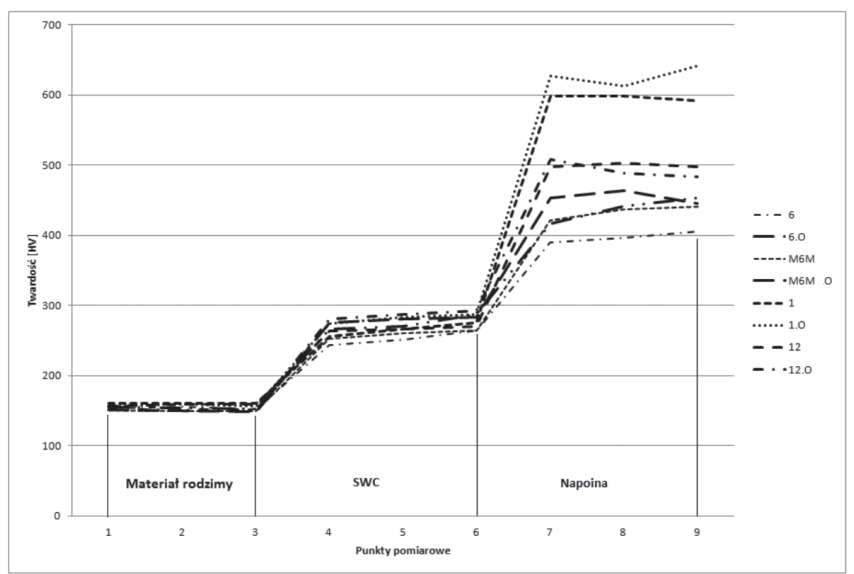

Rys. 7. Wyniki pomiarów twardości

Fig. 7. Results of hardness measurements

\section{Podsumowanie}

Do napawania pierścieni siedliska zastosowano stellity o różnym składzie chemicznym, co było związane z różnym przeznaczeniem elementów napawanych. Stellit EL-Co1W (1) jest stosowany w produktach narażonych na najszybsze zużycie, co jest zwiazane z pracą w środowisku mocno zanieczyszczonym. Pozostałe stellity stosuje się zamiennie w wyrobach mniej narażonych na zużycie.

Przeprowadzone badania wykazały występowanie w napoinach struktury wielofazowej w układzie dendrytycznym. Jest to roztwór stały chromu i wolframu w kobalcie, w którym dodatkowo utworzyły się umacniające go węgliki chromu i wolframu. W strukturach strefy wpływu ciepła zaobserwowano występowanie bainitu i ferrytu. Struktury charakterystyczne dla stopów Co, Cr w stanie lanym cechują się znaczną twardością, co potwierdziły wykonane pomiary.

Największą twardość, dochodzącą do 600HV, ma napoina wykonana ze stellitu 1. Jest to związane z największą zawartością chromu i wolframu w stellicie, a tym samym z większą ilością węglików w napoinie. Napoiny ze stellitów oznaczonych 6 i 6M, o zbliżonym składzie chemicznym, mają porównywalną twardość, wahającą się od 390HV do 440HV, natomiast napoina ze stellitu 12 ma twardość około $500 \mathrm{HV}$.

Przeprowadzona obróbka ciepln, której celem było usunięcie naprężeń spawalniczych, nie spowodowała zmian w strukturach napoin. Zaobserwowano jedynie nieznaczną różnicę twardości.

Przeprowadzone badania pozwoliły sformułować następujące wnioski:

- Struktura napoin wykonanych z różnych stellitów jest podobna, różni się jedynie wielkością i ilością faz.

- Najwyższą twardość ma napoina ze stellitu 1, zawierająca największą ilość chromu i wolframu.

- Zastosowana obróbka cieplna nie wprowadziła znaczących zmian w strukturach i twardości napoin.

\section{Literatura}

[1] Klimpel A.: Spawanie, zgrzewanie i cięcie metali. WNT. Warszawa, 1999.

[2] Kucharczyk W., Mazurkiewicz A., Żurowski W : Nowoczesne materiały

[3] Atesty materiałowe firmy ORIC, Most, DEW. konstrukcyjne-wybrane zagadnienia. Politechnika Radomska, Radom, 2008. 